\title{
Inability of thin-layer chromatography to distinguish feces from congeneric foxes by their bile acid contents
}

\author{
Jaime E. JIMÉNEZ*, José L. YÁÑEZ, and Fabián M. JAKSIĆ
}

Jiménez J. E., Yáñez J. L. and Jaksić F. M. 1996. Inability of thin-layer chromatography to distinguish feces from congeneric foxes by their bile acid contents. Acta Theriologica 41: 211-215.

We used thin-layer chromatography of fecal bile acids in an attempt to separate feces of culpeo fox Pseudalopex culpaeus (Molina, 1782) from those of chilla fox $P$. griseus (Gray, 1837). We tested the method with pure bile acids and with feces from known fox species on two different plate types. Results differed according to the plate type used. The technique failed to distinguish scats from the two fox species. We found variability in the spot pattern of bile acids within species, and within individuals, likely associated to the diet. The location of the spots ( $R f$ values) also varied with the concentration of the sample, and the color and location changed with different plate types. We warn that the thin-layer chromatography of fecal bile acids is still unreliable for distinguishing feces between sympatric carnivores. Hence, we propose to rely on alternative techniques.

Department of Wildlife Ecology and Conservation, University of Florida, Gainesville, FL 32611, USA (JEJ); Sección Zoología, Museo Nacional de Historia Natural, Casilla 787, Santiago, Chile (JLY); Departamento de Ecología, Pontificia Universidad Católica de Chile, Casilla 114-D, Santiago, Chile (FMJ)

Key words: Pseudalopex culpaeus, Pseudalopex griseus, feces, bile acids, chromatography

\section{Introduction}

Carnivore diets have been extensively studied by analyzing prey remains found in feces. However, scats of canids are highly variable morphologically and when species are sympatric, their feces are difficult to distinguish (Murie 1974). Fecal diameter (Weaver and Fritts 1979, Danner and Dodd 1982, Jiménez 1993) and pH (Green and Flinders 1981) are unreliable characters for separating sympatric canids. The bile acids present in the feces of carnivores, however, are species-specific (Lin et al. 1978 cited in Major et al. 1980) and when dry are very stable (Major et al. 1980, Johnson et al. 1984). Thus, it is feasible to differentiate feces of some species by using the thin-layer chromatography technique (TLC) of fecal bile acids (Kritchevsky et al. 1963, Chavez and Krone 1976). Capurro et al. (in press) found that this technique can be used to separate feces of five South

\footnotetext{
*Present address: Department of Fisheries and Wildlife and Ecology Center, Utah State University, Logan, UT 84322-5210, USA
} 
American canids. Here, we test the TLC of fecal bile acids as a method for distinguishing feces from the sympatric and congeneric culpeo Pseudalopex culpaeus (Molina, 1782) and chilla fox P. griseus (Gray, 1837) in north-central Chile (Jiménez 1993).

\section{Material and methods}

We followed the TLC technique described by Major et al. (1980). Initially, we used Macherey-Nagel (Düren, Germany) pre-coated TLC plates SIL G-25 UV 254 . Later, we used Merck (Germany) pre-coated TLC plates silica gel $60 \mathrm{~F}_{254}$, because of the initial failure to distinguish species-specific bile acid spot patterns with the SIL G-25 UV 254 plates. Both the color of the spots and the distances migrated by the samples were recorded under a UV light. The solvent front was recorded immediately after the run.

The $R f$ value is the ratio of the distance travelled by the sample relative to the distance moved by the solvent front. It measures the relative migration ability of the compound on the plate. Individual compounds in a mixture segregate by their differential movement ability.

Ten samples were run in each of 12 plates. Samples were deposited on the plates with a Hamilton syringe (with a $1 \mu \mathrm{l}$ error). Ten, $20,30,40,60$, and $90 \mu \mathrm{l}$ of $5 \mathrm{mg} / \mathrm{ml}$ concentration of the standards were run in order to standardize the optimal concentrations for each bile acid. For standardizing the methods, we proceeded by steps.

We ran different bile acid standards in the same plate types and the same standards in different plate types. As standard bile acids, we used purified cholic, dehydrocholic, deoxycholic, lithocholic, cholic methyl ester, and chenodeoxycholic acid from SIGMA (bile acid kit Sigma 091H9001, USA). A mixture of all standards was also tested using 20,40 , and $60 \mu \mathrm{lof} 5 \mathrm{mg} / \mathrm{ml}$ concentration. Thereafter, separate standards were run in the same plates with feces of known chillas and culpeos. Different feces from the same fox were also used.

We used culpeo and chilla feces from captive animals in the Santiago Zoo, from free-ranging culpeos in Fray Jorge National Park ( $30^{\circ} 38^{\prime} \mathrm{S}, 71^{\circ} 40^{\prime} \mathrm{W}, 400 \mathrm{~km} \mathrm{~N}$ of Santiago), where only culpeo is present, and from foxes trapped at the Chinchilla National Reserve (at Aucó, $31^{\circ} 30^{\prime} \mathrm{S}, 71^{\circ} 06^{\prime} \mathrm{W}, 300$ $\mathrm{km} \mathrm{N}$ of Santiago; Jiménez 1993). As a test, we ran known samples with unknown feces collected at Aucó.

Feces from conspecific captured foxes that had remains of different prey types (eg feces made up of fruit remains vs mammal remains vs insect remains) provided insights for addressing the effect of prey type in the pattern of TLC spots obtained.

\section{Results}

Using the standard bile acids, different results were obtained with different plates. $R f$ values (Rank sum test, Hollander and Wolfe 1973; $\mathrm{W} \geq 3, p<0.05$ ), colors, and numbers of spots changed substantially (Table 1 ). $R f$ values also changed with the concentration of the sample. $R f$ values decreased inversely with the concentration of the sample used (Table 1; eg for chenodeoxycholic acid on Macherey-Nagel plates, $r=-0.993, n=5, p=0.0008$, not shown). Even at the same concentration, and for the same sample and plate type used, there was high variability in the $R f$ values (as an example see results on Merck plates in Table 1). Standards when run together showed different spot pattern and $R f$ values than if they were run separately. 
Table 1. Colors under UV light and $R f$ values of spots for different amounts $(\mu \mathrm{l}$ of $5 \mathrm{mg} / \mathrm{ml}$ concentration) of standard bile acids. Results are from two different TLC plate brands. Data shown here are representative of several other runs. The symbol "-" indicates that the test was not run for that concentration.

\begin{tabular}{|c|c|c|c|c|c|c|c|c|c|c|}
\hline \multirow{3}{*}{ Bile acid } & \multicolumn{7}{|c|}{ Macherey-Nagel SIL G-25 UV254 plates } & \multicolumn{3}{|c|}{ Merck $60 \mathrm{~F}_{254}$ plates } \\
\hline & \multirow{2}{*}{ Color } & \multicolumn{6}{|c|}{$\mu \mathrm{l}$} & \multirow{2}{*}{ Color } & \multicolumn{2}{|c|}{$\mu \mathrm{l}$} \\
\hline & & 10 & 20 & 30 & 40 & 60 & 90 & & 30 & 30 \\
\hline \multirow[t]{2}{*}{ Lithocholic } & Blue & - & - & 0.880 & - & 0.867 & - & Fluorescent & 0.813 & 0.736 \\
\hline & Blue & - & - & 0.741 & - & 0.741 & - & Fluorescent & 0.761 & 0.684 \\
\hline Deoxycholic & Yellow & - & - & 0.590 & - & 0.566 & - & Yellow & 0.497 & 0.491 \\
\hline \multirow[t]{2}{*}{ Chenodeoxycholic } & Blue & - & 0.513 & 0.506 & 0.500 & 0.488 & - & Yellow & 0.465 & 0.459 \\
\hline & & & & & & & & Fluorescent & 0.115 & 0.127 \\
\hline Cholic & Yellow & - & - & 0.491 & - & 0.487 & 0.484 & Yellow & 0.136 & 0.151 \\
\hline Cholic methyl ester & Brown & - & 0.306 & 0.269 & - & 0.270 & - & Yellow & 0.209 & 0.205 \\
\hline \multirow[t]{2}{*}{ Dehydrocholic } & Brown & 0.171 & 0.171 & 0.171 & 0.171 & - & - & Yellow & 0.545 & 0.503 \\
\hline & & & & & & & & Fluorescent & 0.487 & 0.454 \\
\hline
\end{tabular}

Feces of chilla and culpeo could not be distinguished by the bile acids pattern using TLC (Table 2). There was no clear pattern for the spots produced by feces from either known chillas or culpeos. Further, there were important differences in the spot patterns of different feces from the same individual (Table 2). The results presented in Table 2 were consistent with several other runs with different plates and combinations of fox species and individuals. By running several samples from conspecific foxes with known diets, we found that foxes (probably different individuals) fed on different diets produced different spot patterns of bile acids.

Table 2. Colors and $R f$ values of spots from control culpeo fox (CU) and chilla fox $(\mathrm{CH})$ feces run on the same Merck plate. Different numbers represent feces from different individuals. Different superscripts $\left({ }^{\mathrm{a}, \mathrm{b}}\right)$ indicate separate feces from the same individual. The symbol "-" indicates that no spot was detected.

\begin{tabular}{lcccccc}
\hline Color & CU1 $^{\mathrm{a}}$ & CU1b & CU2 & CH1 $^{\mathrm{a}}$ & CH1b & CH2 \\
\hline Red & 0.891 & 0.858 & 0.892 & 0.901 & 0.893 & 0.890 \\
Fluorescent & - & 0.768 & 0.759 & - & 0.774 & 0.816 \\
Fluorescent & 0.655 & 0.652 & 0.639 & 0.677 & 0.667 & - \\
Yellow & 0.485 & 0.529 & 0.494 & 0.497 & 0.516 & 0.497 \\
Fluorescent & - & 0.452 & - & 0.429 & 0.440 & 0.436 \\
Fluorescent & 0.346 & 0.400 & - & - & - & - \\
Fluorescent & - & 0.277 & - & 0.255 & 0.270 & - \\
Fluorescent & - & - & - & 0.193 & 0.201 & - \\
Fluorescent & 0.121 & 0.129 & 0.121 & 0.118 & 0.126 & 0.129 \\
& & & & & &
\end{tabular}


Fox feces containing fruits of Porlieria produced larger spots with lower $R f$ in addition to those produced by feces with vertebrate remains only.

\section{Discussion}

Because results varied with the plate used, the plate type is obviously important. This point is relevant to highlight, because the plate type and brand are not usually described in the literature. Thus, $R f$ values from other studies may not be used as standards for comparisons. Another aspect that needs to be considered is the concentration of the sample used. For individual studies, it is necessary to standardize the method to render it useful. Further, because of the high variability among samples, which is generally not reported in the literature, several runs must be made from the same sample to obtain an average $R f$ value. The lack of clear separation of standards when run together may reflect interference among bile acids as indicated by Major et al. (1980). Also, too much concentration of the sample may produce interference and hence changes in $R f$ value.

The effect of fecal contents (ie diet type) or contamination from anal glands products has not been considered in previous research for interpreting similar results (but see Quinn and Jackman 1994). Feces that contain fatty acids and esters as products of the diet (ie certain fruits such as Porlieria chilensis in the feces of Aucó foxes) will produce a distinctive large dark spot, which will mask those from bile acids. Therefore, by keeping the diet constant, some patterns may emerge. However, this is not possible to do with feces from unknown free-ranging carnivores. Indeed, it has been shown in coyotes Canis latrans that diet type ("previous diet experience") alone can change the bile acids spot patterns (Quinn and Jackman 1994). These authors cautioned that differences in diet might thus render the technique useless. Our results on Pseudalopex feces support their claim. In addition, several biochemists at the Catholic University of Chile (ie P. Bull, M. Bronfman, and F. Nervi, pers. comm.) concurred that qualitative differences in these conservative bile acids of congeneric vertebrates should not be expected.

The quantification with gas chromatography of the amount of different bile acids in the feces might distinguish feces of closely related species. But even by using this method, it is difficult to distinguish congeneric felids (Johnson et al. 1984: 242). In addition, for this purpose, the use of gas chromatography is prohibitively expensive. Tagging individuals with species-specific radio-isotopes is another alternative for separating feces from sympatric congeneric carnivores (Conner 1982) or by combining feces diameter and the location of the feces within known radio-collared fox territories (Jiménez 1993).

Contrary to the findings of Capurro et al. (in press), we conclude that the TLC cannot be used for distinguishing feces from chilla and culpeo. There is too much variability in the spot pattern, even among feces produced by the same individual. 
Part of this variability, which may override interspecific differences, might be explained by the type of food consumed as found by Quinn and Jackman (1994) for coyotes. Consequently, we warn that thus far, the use of bile acid to distinguish feces from sympatric free ranging carnivores is still an unsuitable technique.

Acknowledgements: This research was funded by grants from the Lincoln Park Scott Neotropic Fund and the Tropical Conservation and Development Program of the University of Florida to J. E. Jiménez, and from the Chilean Fund for Scientific and Technological Development (FONDECYT 92-0038) to J. L. Yáñez. This was part of J. E. Jiménez M Sc research and was written under tenure of a Fulbright fellowship. C. Muñoz and B. Saavedra assisted in the field and K. Miller, Z. Pucek, W. Stone, and two anonymous reviewer improved earlier drafts. C. Muñoz and S. Silva provided scats from known chillas and culpeos, and M. Jordán provided laboratory space and facilities at Universidad Católica de Chile. The Chilean Forest Service (CONAF) allowed us to work at the Chinchilla National Reserve.

\section{References}

Capurro A. F., Romero M. S., Novaro A. J. and Travaini A. (in press). Biochemical identification of feces of Neotropical carnivores. Mammalia.

Chavez M. N. and Krone C. L. 1976. Silicic acid thin-layer chromatography of conjugate and free bile acids. Journal of Lipid Research 17: 545-547.

Conner M. C. 1982. Determination of bobcat (Lynx rufus) and raccoon (Procyon lotor) population abundance by radioisotope tagging. M Sc thesis, University of Florida, Gainesville: 1-55.

Danner D. A. and Dodd N. 1982. Comparison of coyote and gray fox scat diameters. Journal of Wildlife Management 46: 240-241.

Green J. S. and Flinders J. T. 1981. Diameters and $\mathrm{pH}$ comparisons of coyote and red fox scats. Journal of Wildlife Management 45: 765-767.

Hollander M. and Wolfe D. A. 1973. Nonparametric statistical methods. John Wiley and Sons, New York: 1-503

Jiménez J. E. 1993. Comparative ecology of Dusicyon foxes at the Chinchilla National Reserve in northcentral Chile. M Sc thesis, University of Florida, Gainesville: 1-168.

Johnson M. K., Belden R. C. and Aldred D. R. 1984. Differentiating mountain lion and bobcat scats. Journal of Wildlife Management 48: 239-244.

Kritchevsky D., Martak D. S and Rothblat G. H. 1963. Detection of bile acids in thin-layer chromatography. Analytical Biochemistry 5: 388-392.

Major M., Johnson M. K., Davis W. S. and Kellogg T. F. 1980. Identifying scats by recovery of bile acids. Journal of Wildlife Management 44: 290-293.

Murie O. J. 1974. A field guide to animal tracks. The Peterson Field Guide Series. Sec. ed. Houghton Mifflin Company, Boston: 1-375.

Quinn T. and Jackman W. R. 1994. Influence of diet on detection of fecal bile acids by thin-layer chromatography. Journal of Wildlife Management 58: 295-299.

Weaver J. L. and Fritts S. H. 1979. Comparison of coyote and wolf scat diameters. Journal of Wildlife Management 43: 786-788.

Received 11 October 1995, accepted 18 March 1996. 